\title{
Memory effect in silicon nitride deposition using ICPCVD technique
}

\author{
Sunil Kumar ${ }^{1}$ - D. S. Rawal ${ }^{1} \cdot$ Hitendra K. Malik $^{2} \cdot$ Rajeev Sanwal $^{1}$ - S. A. Khan ${ }^{3} \cdot$ Seema Vinayak $^{1}$
}

Received: 7 August 2019 / Accepted: 24 September 2019 / Published online: 5 October 2019

(c) The Author(s) 2019

\begin{abstract}
In this study, a plasma-based low-temperature, low-pressure SiN film deposition is investigated for device applications. Ammonia, nitrogen and silane are being used for optimization of the quality of SiN film for device passivation by ICPCVD. Characterization of SiN film is done using elastic recoil detection analysis, AFM, FTIR and ellipsometry. The effect of previous process parameters on subsequent process is called memory effect, which has been investigated by all the characterization techniques. During deposition, this effect has been observed for the same parameters that are used to maintain the stoichiometry of the film. It has been observed that some of the residues of gases used for SiN deposition remain present even after the deposition in the chamber and are carried over for the next deposition process and alter the film property, though parameters such as flow rate, temperature, pressure and time remain fixed. This memory effect alters the film surface roughness and stoichiometry thus affecting device characteristics after passivation.
\end{abstract}

Keywords Silicon Nitride (SiN) $\cdot$ ICPCVD $\cdot$ PECVD $\cdot$ ERDA $\cdot$ HEMT $\cdot$ Current collapse

\section{Introduction}

The silicon nitride dielectric films are being used widely for electrical isolation, mask fabrication and as protection layers in semiconductor device technology [1]. The important and crucial application of these plasma-deposited silicon nitride dielectric films is for passivation of devices [2]. These films can be deposited with different composition and by different techniques as per the requirement. Silicon nitride $\left(\mathrm{Si}_{3} \mathrm{~N}_{4}\right)$ is being used in GaAs HEMTs (high-electron mobility transistors) and GaN HEMTs-based MMICs (microwave monolithic integrated circuits) for device passivation. These films reduce the surface trap density of HEMT structure by reducing the surface states at the surface, which is the source of current collapse or knee walkout problems $[3,4]$. Silicon nitride (SiN) film composition and quality affect the performance of the device [5]. There are a number of studies reported in the literature for GaN HEMT gate passivation model using PECVD SiN to reduce reverse leakage

Sunil Kumar

sundrdo@gmail.com

Solid State Physics Laboratory, Delhi, India

2 Department of Physics, Indian Institute of Technology Delhi, Delhi, India

3 Interstate University Accelerator Center, Delhi, India current $[6,7]$. There are very few studies that report results of ICPCVD passivation effect. Chao et al. [8] have reported recently the impact of stress in SiN film deposition by ICPCVD. Memory effect is being very crucial for repeatability and reproducibility of plasma process, but no report is yet published of ICPCVD passivation to the best of our knowledge. The present study reports the detailed systematic study of memory effect of ICPCVD process for SiN passivation $[9,10]$. The main aim of the present study is to develop a process free from memory effect to mitigate the problem of current collapse/knee walkout in in-house fabricated GaN HEMTs.

\section{Experiment details}

The inductively coupled plasma chemical vapor deposition technique (ICPCVD) based on high-density plasma is used, and we have used Oxford make ICPCVD system for silicon nitride deposition which helps depositing highly dense silicon nitride films with less content of hydrogen percentage compared to conventional PECVD technique [11, 12]. Silane $\left(\mathrm{SiH}_{4}\right)$ and nitrogen $\left(\mathrm{N}_{2}\right)$ gases have been used instead of silane and ammonia to minimize the incorporation of hydrogen percentage in the film. SENTECH Adv500 Ellipsometer is used for measuring refractive index and thickness of the 
grown films. Films are grown to have stoichiometric silicon nitride with refractive index $\sim 2.0$ and thickness $\sim 1000 \AA$. To emphasize the memory effect simultaneously, three runs on GaAs wafer for silicon nitride deposition are carried out with fix parameters for sample A, sample B and sample C, i.e., gases flow rate, temperature, pressure, frequency, power and time. Silane at the rate of $140 \mathrm{sccm}$ and nitrogen at the rate of $18 \mathrm{sccm}$ are used at pressure $\sim 10 \mathrm{mTorr}$, and temperature $\sim 100{ }^{\circ} \mathrm{C}$ for $10 \mathrm{~min}$ for all the three runs. $\mathrm{SiH}_{4}$ and $\mathrm{N}_{2}$ undergo a chemical reaction under the activation action of $\mathrm{RF}$ plasma [13]. The possible chemical reaction of $\mathrm{SiH}_{4}$ and $\mathrm{N}_{2}$ that takes place in plasma is as follows:

$3 \mathrm{SiH}_{4}+2 \mathrm{~N}_{2} \rightarrow \mathrm{Si}_{3} \mathrm{~N}_{4}+6 \mathrm{H}_{2}$.

The characterization of deposited silicon nitride is carried out using ellipsometric measurement for refractive index and thickness, FTIR for bonding strength and AFM for roughness of the deposited film, ERDA (elastic recoil detection analysis) for investigating quantitatively the proportion of silicon, nitrogen and hydrogen present in the deposited films $[14,15]$.

Elastic recoil detection analysis (ERDA) is a technique specially suited for depth profiling of light elements, which overcomes the limitations of Rutherford backscattering (RBS) technique [16].

High-energy heavy ions can induce structural and compositional changes in the material through which they pass. The study of high-energy ions induced compositional changes in materials can be carried out using ERDA. In our case, a telescope detector was used to identify different recoils originating from a sample. Mostly, it comprises two detectors named as $\Delta E$ and $E_{\text {rest }}$ sub-detectors and therefore called as $\Delta E-E$ detector telescope. The recoils entering the detector lose a fraction of their energy in $\Delta E$ detector and the rest of it in $E_{\text {rest }}$ detector. Energy lost in the first detector was found to be proportional to $\mathrm{MZ}^{2}$, where $\mathrm{M}$ and $\mathrm{Z}$ are the mass and atomic number of the recoil particle, respectively, which allows for the identification of elements.

\section{Result and discussion}

\section{Ellipsometry}

Refractive index measurements show variation in index for the first sample to third sample, which was grown one after another under the same conditions. The refractive index was found to vary from $\sim 1.89$ to $\sim 2.0$, while thickness was almost $\sim 100 \mathrm{~nm}$. The effect on the refractive index is attributed to the foreign species like carbon and oxygen present in the chamber when earlier depositions have been carried out.

The refractive index and thickness are measured by laser ellipsometer using laser radiation of $632 \mathrm{~nm}$ wavelength. In our case, the refractive index and the thickness of $\mathrm{Si}_{3} \mathrm{~N}_{4}$ thin films deposited on GaAs wafers are measured. For sample A, the measured values for refractive index and thickness are $\sim 1.89$ and $\sim 1050 \AA$, respectively. For the next two samples, all the deposition parameters are kept the same and clean GaAs wafers are used for silicon nitride deposition. The variation in refractive index and thickness is determined. Sample $\mathrm{B}$ is found to have refractive index $\sim 1.95$, whereas sample $\mathrm{C}$ had refractive index $\sim 2.0$. Slight change in thickness is also observed with $1150 \AA$ A for sample B and $1100 \AA$ for sample C.

\section{FTIR spectra}

The FTIR spectra have been used to determine the chemical bonding among the various elements present in silicon nitride thin films. Figure 1 shows the FTIR spectra for silicon nitride films in the range of $400-6500 \mathrm{~cm}^{-1}$; these films are deposited by ICPCVD at $100{ }^{\circ} \mathrm{C}$. The absorption peaks are observed at $830 \mathrm{~cm}^{-1}$, in all the films, referring to the stretching vibration mode of the $\mathrm{Si}-\mathrm{N}$ bond. In addition to above peaks, we observed the $\mathrm{Si}-\mathrm{H}$ wagging mode near $2180 \mathrm{~cm}^{-1}$ and $\mathrm{N}-\mathrm{H}$ stretching mode around $3340 \mathrm{~cm}^{-1}$. Slightly higher amplitude at these wave numbers for corresponding peaks is also observed, and the positions of the corresponding absorption peaks of the films may be due to change in stoichiometry of the films $[17,18]$.

\section{AFM measurement}

In order to understand the topography of deposited thin films, atomic force microscopy (AFM) studies are carried out. The AFM images shown in Fig. 2 reveal variation in grain size on the surface of silicon nitride films. The scanned regions in each case are taken as $2 \times 2 \mu \mathrm{m}^{2}$ and $5 \times 5 \mu \mathrm{m}^{2}$. The surface roughness of silicon nitride thin films from these AFM measurements is found to be $0.9 \mathrm{~nm}, 0.85 \mathrm{~nm}$ and $0.80 \mathrm{~nm}$, respectively, for the samples A, B and C. It can be

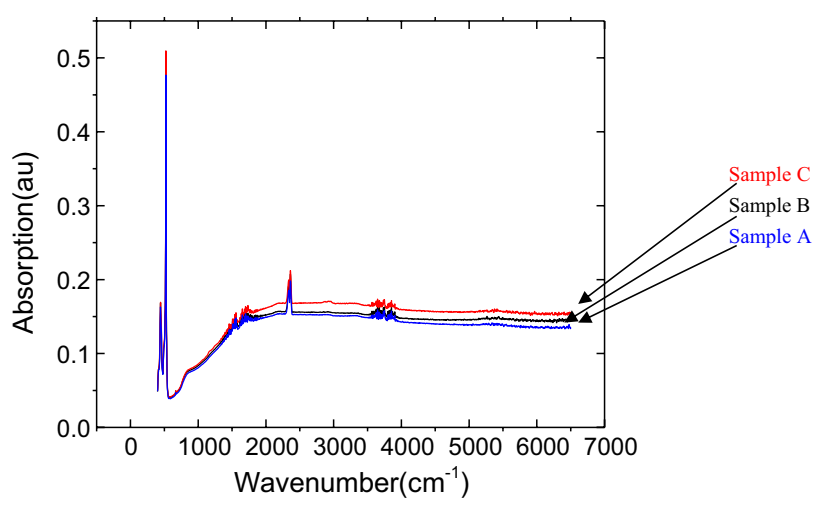

Fig. 1 FTIR spectra for samples A, B and C showing $\mathrm{Si}-\mathrm{N}, \mathrm{Si}-\mathrm{H}$ and $\mathrm{N}-\mathrm{H}$ peaks 

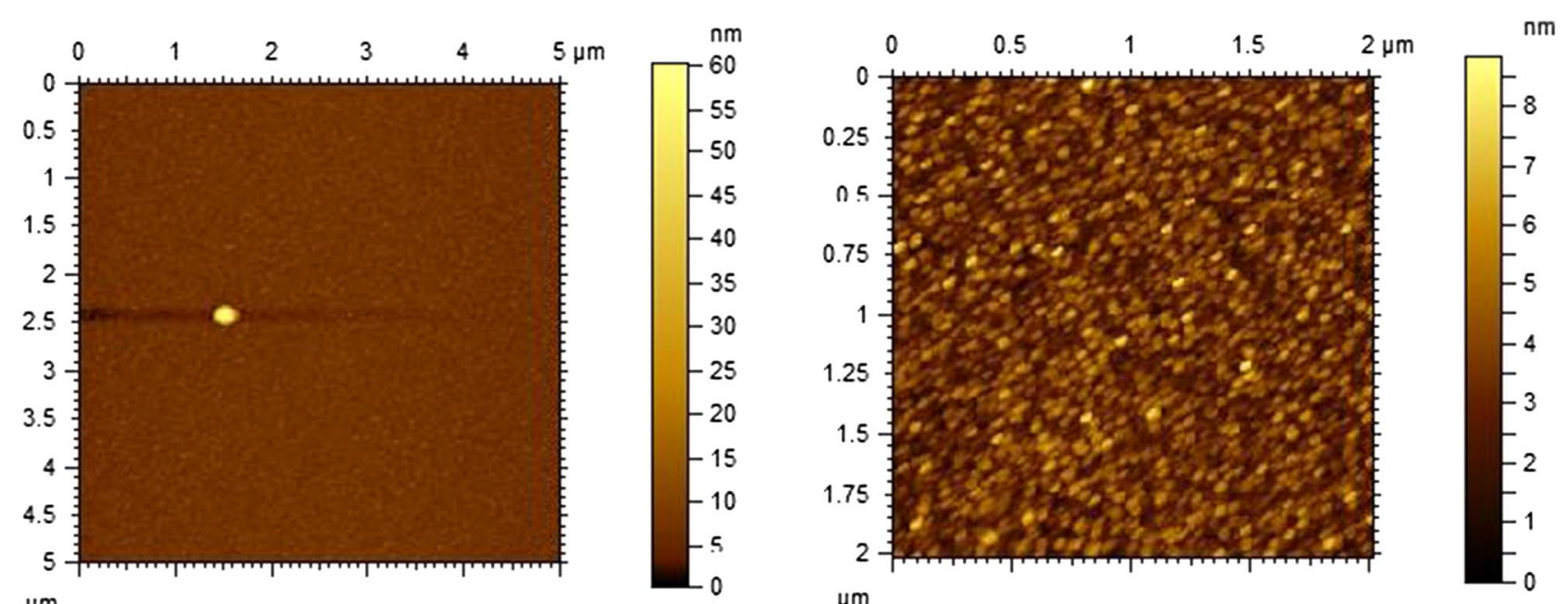

$\mu \mathrm{m}$
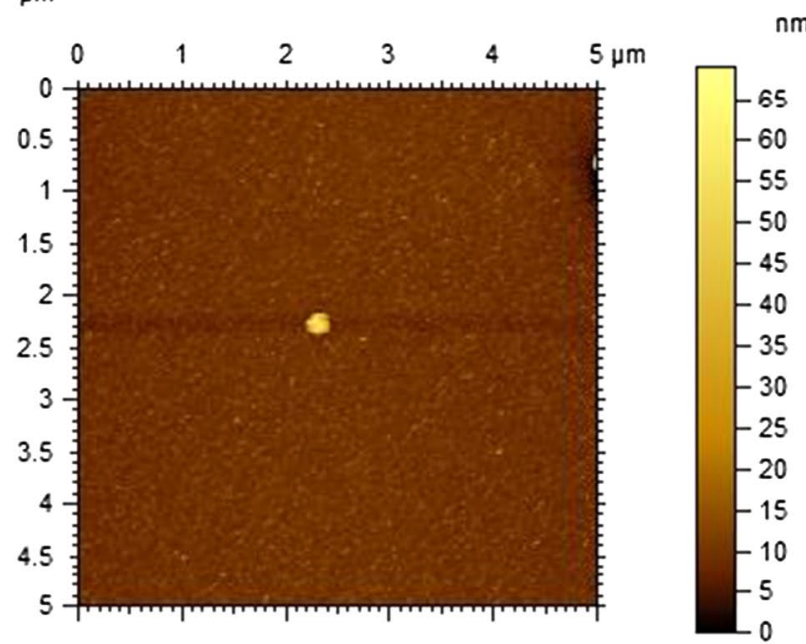

nmSample (A)
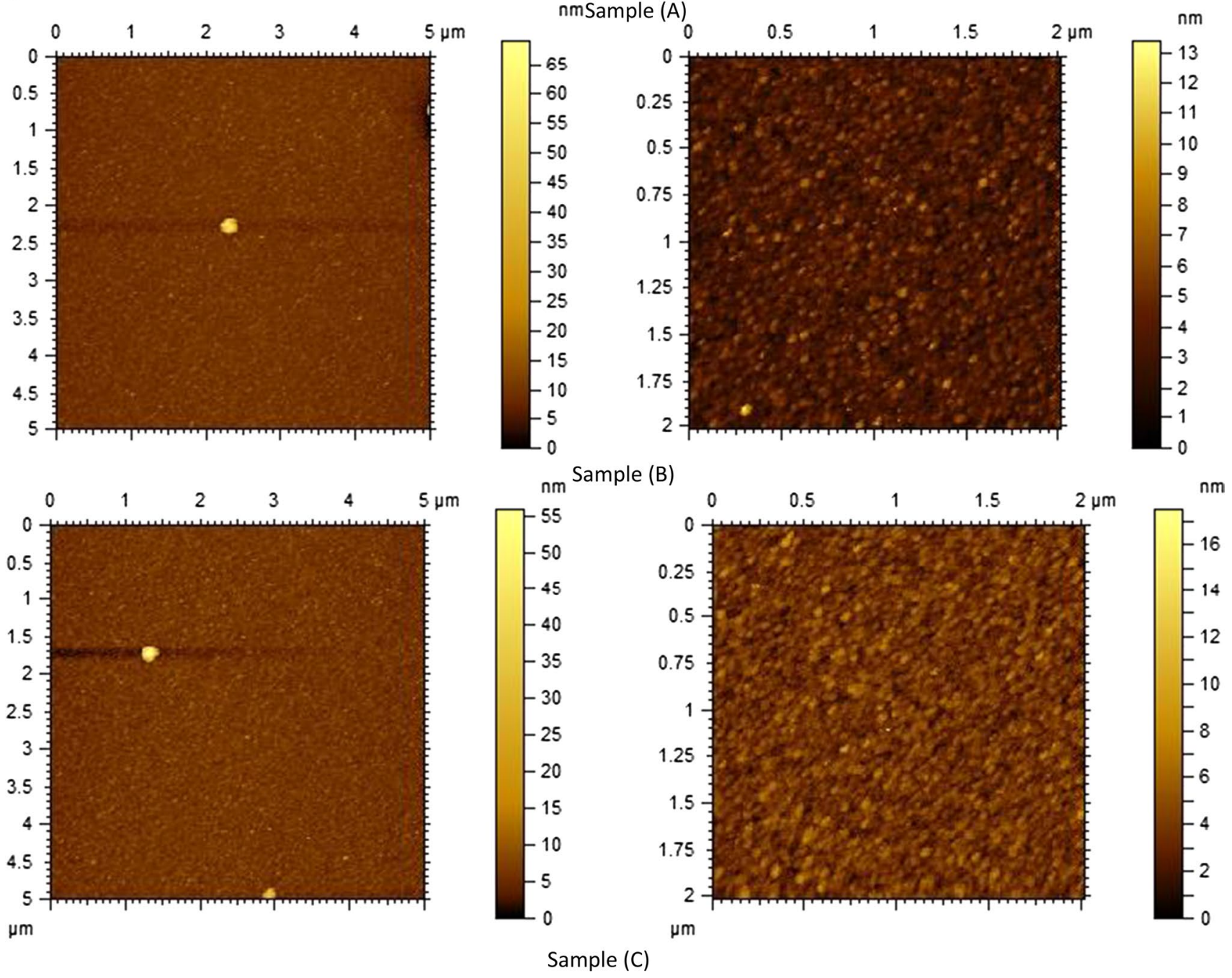

Fig. 2 AFM images of samples A, B and C showing different grain sizes 
said that the films deposited by ICPCVD have larger grain size and surface roughness initially. However, the reduced surface roughness is observed when the process is stabilized which may have led to better stoichiometry of the film.

\section{ERDA technique}

ERDA analysis shows the elemental concentration depth profiles of the deposited $\mathrm{Si}_{3} \mathrm{~N}_{4}$ films [19]. $\mathrm{Ag}^{7+}$ is used to irradiate the sample at $100 \mathrm{MeV}$ energy for $30 \mathrm{~min}$. The area of the irradiated spot was calculated and is found to be $0.0175 \mathrm{~cm}^{2}$. CANDLE software is used to count the total number of blocks in the samples. These blocks are then further divided into approximate blocks of 100, and the total charge, charge per block, $\mathrm{Si}, \mathrm{N}$ and $\mathrm{H}$ values are determined. These are shown in Fig. 3.

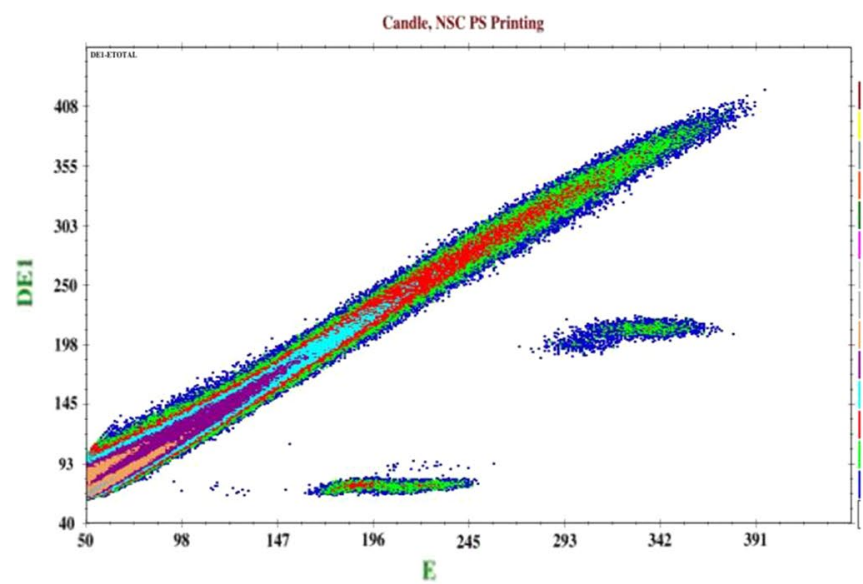

(a)
The total number of ions was calculated using the following formula:

No. of incidentions $=\frac{[\text { current integrator count }(\mathrm{C})]}{7 * 1.6 * 10^{-19}} *\left[\frac{F C L 51}{\text { current }}\right]$.

Fluence is given by:

Fluence $=\frac{\text { total no. of ions }}{\text { area of the spot }}$.

The fluence versus concentration graphs in Fig. 4 shows the areal density of $\mathrm{Si}, \mathrm{N}$ and $\mathrm{H}$ in the samples $\mathrm{A}, \mathrm{B}$ and $\mathrm{C}$. This clearly shows the lowering of hydrogen percentage in sample C compared to sample B and in sample B lower to sample A.

The optimized silicon nitride film was deposited as passivation layer on GaN HEMT devices to mitigate of current

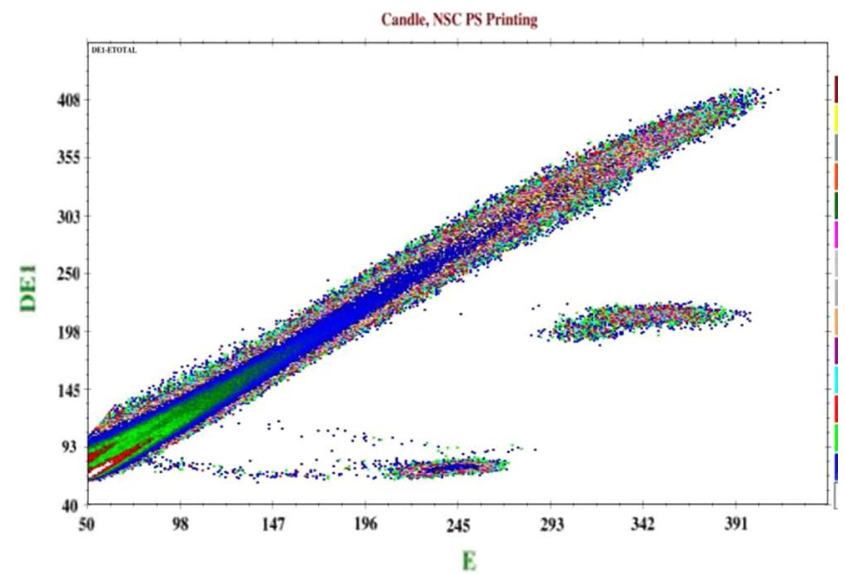

(b)

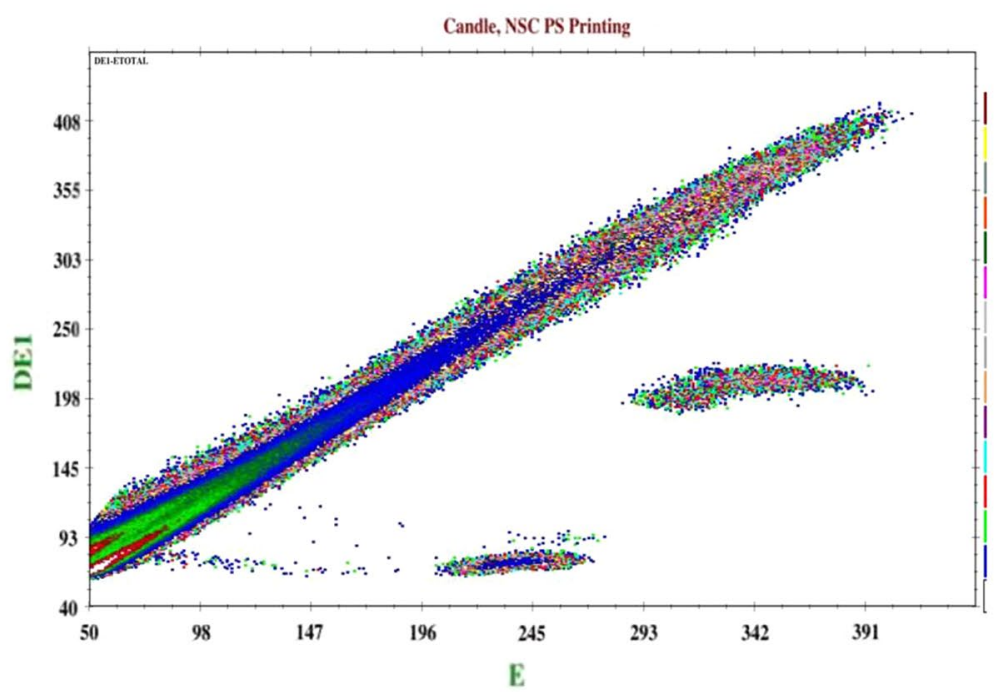

(c)

Fig. 3 Images of ERDA for different samples (a), (b) and (c), two-dimensional $\Delta E-E$ spectrum of recoils from $\mathrm{S}_{\mathrm{i} 3} \mathrm{~N}_{4}$ films deposited on GaAS wafer. The spectrum was obtained using $100 \mathrm{MeV} \mathrm{Ag}^{7+}$ projectiles 

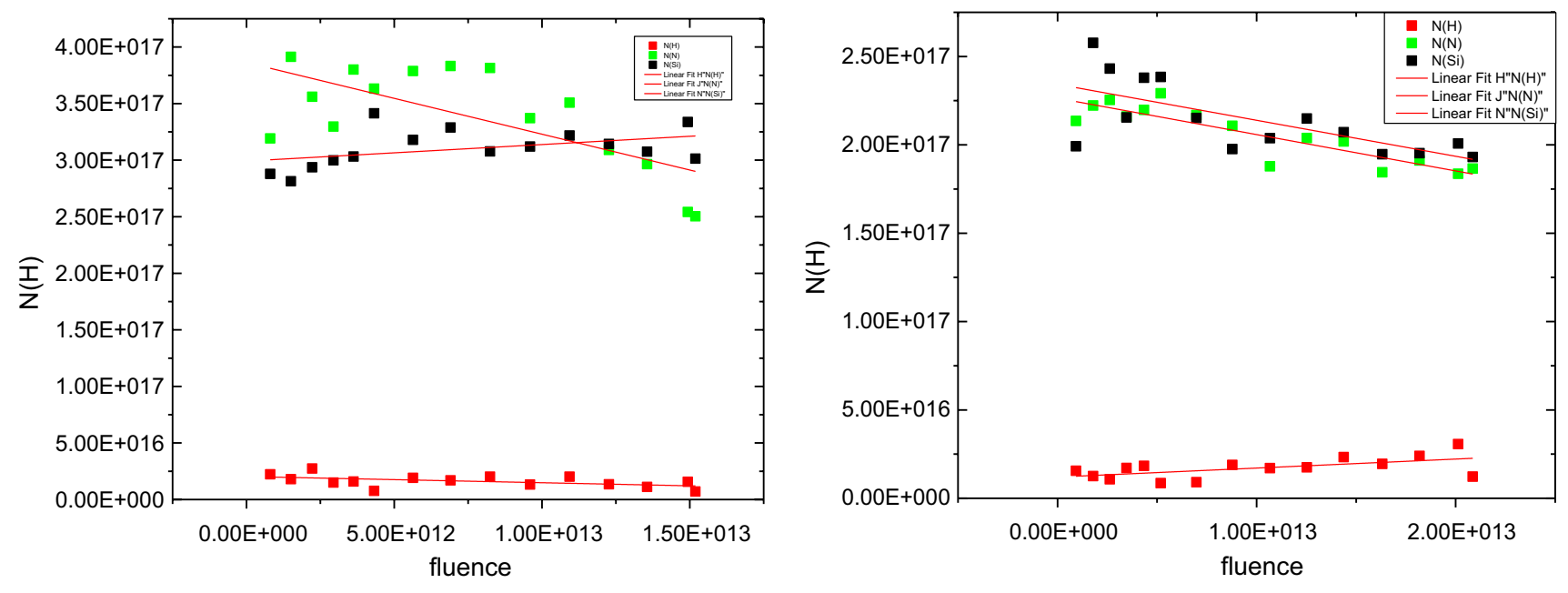

Sample (A)

Sample (B)

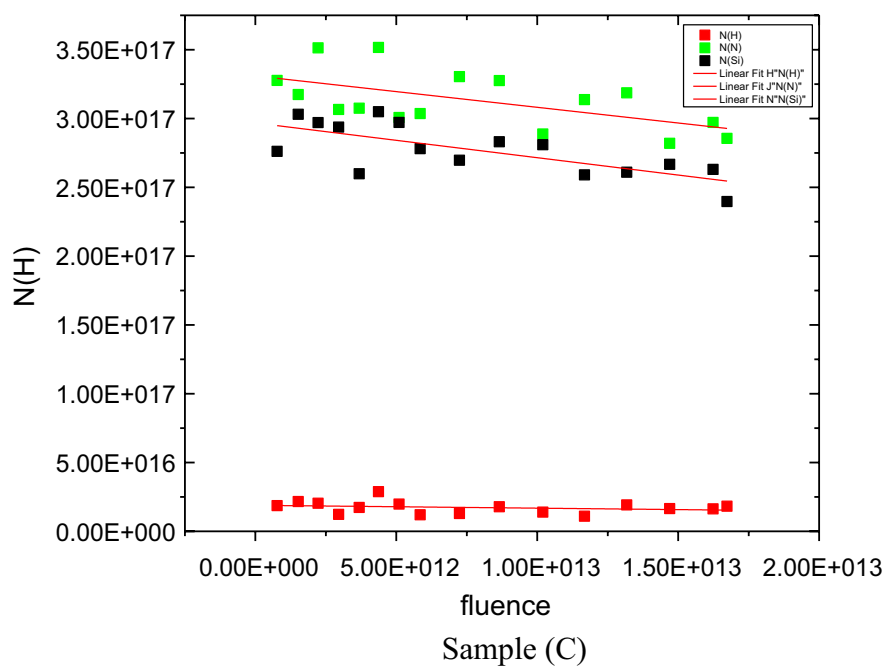

Fig. 4 Analysis for composition in samples $\mathrm{A}, \mathrm{B}$ and $\mathrm{C}$ for $\mathrm{Si}$, N, and $\mathrm{H}$ versus fluence

collapse and knee walkout problem as GaN HEMT devices are severely affected with these problems. The current voltage characteristics in pulse mode shown in Fig. 5 compare the results of device before and after passivation using the optimized silicon nitride film. The current recovery measured here was more than $95 \%$ with negligible knee walkout compared to DC I-V characteristics.

\section{Conclusions}

We have presented a systematic experimental analysis of silicon nitride films deposited by ICPCVD technique. The study shows variation in the composition and quality of the films even with the same deposition parameters. This may be attributed to the residue remained in the deposition chamber and which affect the very quality of the film until stabilized. Elliposemetric measurements have suggested about the film refractive index and thickness, which can be clearly related to density of the film. Lower refractive index films are found to have higher etch rate compared to high refractive index films. ERDA measurement and calculations confirmed the percentage of hydrogen content in the films, and the variation in the refractive index was verified by ellipsometric measurements results. This hydrogen content is initially high, whose incorporation may be attributed to the presence of residuals in the chamber during deposition. Hence, conditioning and stabilization of silicon nitride films are necessary before it can be used for any device application. 


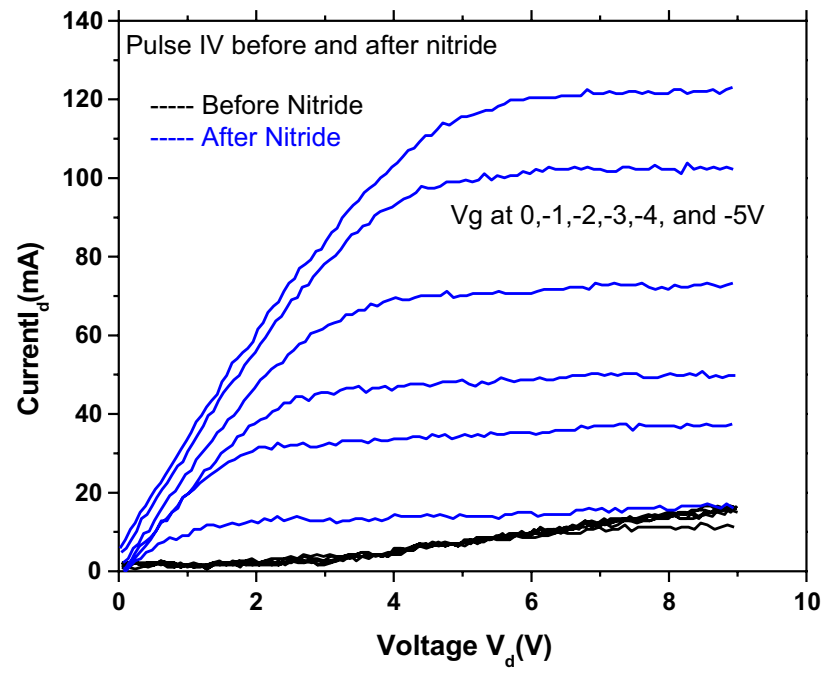

Fig. $5 \mathrm{I}-\mathrm{V}$ characteristics (Pulse $\mathrm{I}_{d}-\mathrm{V}_{d}$ ) of GaN HEMT comparing pulse mode current-voltage before and after optimized silicon nitride passivation

Acknowledgements The authors acknowledge the characterization and MMIC teams from SSPL for their help. We also are thankful to Inter University Accelerator Center (IUAC), Delhi, for allowing us to carry out ERDA experiments.

Open Access This article is distributed under the terms of the Creative Commons Attribution 4.0 International License (http://creativeco mmons.org/licenses/by/4.0/), which permits unrestricted use, distribution, and reproduction in any medium, provided you give appropriate credit to the original author(s) and the source, provide a link to the Creative Commons license, and indicate if changes were made.

\section{References}

1. Liu, L., Liu, W.G., Cao, N., Cai, C.L.: Study on the performance of PECVD silicon nitride thin films. Def. Technol. 9, 121 (2013)

2. Gatabi, I.R., Johnson, D.W., Woo, J.H., Anderson, J.W., Cona, M.R., Piner, E.L., Harris, H.R.: PECVD silicon nitride passivation of $\mathrm{AlGaN} / \mathrm{GaN}$ heterostructures. IEEE Trans. Electron Devices 60(3), 1082 (2013)

3. Pei, Y., Rajan, S., Higashiwaki, M., Chen, Z., DenBaars, S.P., Mishra, U.K.: Effect of dielectric thickness on power performance of AlGaN/GaN HEMTs. IEEE Electron Device Lett. 30(4), 313 (2009)

4. Bogaerts, A., Neyts, E., Gijbels, R., Mullen, J.V.D.: Gas discharge plasmas and their applications. Spectro Chimica Acta Part B 57(4), 609 (2002)
5. Hashizume, T., Nishiguchi, K., Kaneki, S., Kuzmik, J., Yatabe, Z.: State of the art on gate insulation and surface passivation for GaN- based power HEMTs. Mater. Sci. Semicond. Proc. 78, 85 (2018)

6. Hua, M., Liu, C., Yang, S.: GaN based metal insulator semiconductor high electron mobility transistors using low pressure chemical vapor deposition $\mathrm{SiNx}$ as gate dielectric. Electronics Device Lett. 36(5), 448 (2015)

7. Zhang, S., Wei, K., Xiao, Y., Ma, X.H., Zhang, Y.C., Liu, G.G., Lei, T.M., Zheng, Y.K., Huang, S., Wang, N., Asif, M., Liu, X.Y.: Effect of SiN: Hx passivation layers on the reverse gate leakage current in GaN HEMTs. Chin. Phys. B 27(9), 097309 (2018)

8. Chao, S.J., Li, X., Guiney, I., Floros, K., Hemakumara, D., Wallis, D.J., Humphreys, C., Thayne, I.G.: Impact of stress in ICP-CVD SiNx passivation films on the leakage current in $\mathrm{AlGaN} / \mathrm{GaN}$ HEMTs. Electron. Lett. 54(15), 947 (2018)

9. Zambom, L., Mansano, R., Furlan, R.: Silicon nitride deposited by inductively coupled plasma using silane and nitrogen. Vacuum 65, 123 (2002)

10. Lee, J., Mackenzie, K., Johnson, D., Pearton, S., Sarrerat, J., Ren, F.J.: Low temperature silicon nitride and silicon dioxide film processing by inductively coupled plasma chemical vapor deposition. Electrochem. Soc. 147, 1481 (2000)

11. Gupta, M.: The preparation, properties and application of the silicon nitride thin films deposited by plasma enhance chemical vapor deposition. Thin Solid Films 204, 77 (1991)

12. Yota, J., Hander, J., Saleh, A.A.: A comparative study on inductively-coupled plasma high-density plasma, plasma-enhanced, and low pressure chemical vapor deposition silicon nitride films. J. Vac. Sci. Technol., A 18, 372 (2000)

13. Karouta, F., Vorta, K., Tian, J., Jagadish, C.: Structural, compositional and optical properties of PECVD silicon nitride layers. J. Phys. D Appl. Phys. 45(44), 445301 (2012)

14. Awasthi, D.K., Assmann, W.: ERDA with swift heavy ions for materials characterization. Curr. Sci. 80(12), 1532 (2001)

15. Ammar, A.A., Gupta, R.K., Barnes, R.M.: Elimination of Boron memory effect in inductively coupled plasma mass specterometry by ammonia gas injection into the spray chamber during analysis. Spectrochimica Acta Part B 55(6), 629 (2000)

16. Khan, S.A., Kumar, M., Awasthi, D.K.: Development of a position sensitive detector telescope for ERDA based on-line monitoring of swift heavy ions induced modifications. Nucl. Instrum. Methods Phys. Res. B 266(8), 1912 (2008)

17. Claassen, W.A.P., Valkenburg, W.G.J.N., Habraken, F.H.P.M., Tamminga, Y.: Characterization of plasma silicon nitride layers. J. Electrochem. Soc. Solid State Sci. Technol. 130(12), 2419 (1983)

18. Verlan, V., Van der Werf, C.H.M., Arnoldbik, W.M., Goldbach, H.D., Schropp, R.E.I.: Unambiguous determination of Fouriertransform infrared spectroscopy proportionality factors: the case of silicon nitride. Phys. Rev. B 73, 195333 (2006)

19. Ionescu, M., Richard, B., Mclntosh, K., Siegele, R., Stelcer, E., Cohen, D.D., Chandra, T.: Hydrogen measurements in $\mathrm{SiN}_{\mathrm{x}}$ : H/ Si thin films by ERDA. Mater. Sci. Forum 539-543, 3551 (2007)

Publisher's Note Springer Nature remains neutral with regard to jurisdictional claims in published maps and institutional affiliations. 